\title{
Tres veranos de calor intenso
}

Federico PATÁN

Universidad Nacional Autónoma de México

Hay, desde luego, muchas razones para leer narrativa. La única de apariencia inocente es aquélla escudada en el hecho sencillo de ayudarse a pasar bien unas horas. El vicio impune llamó a tal experiencia W. H. Auden, si la memoria no nos engaña mediante una equivocación. O pudiéramos definir a la lectura como satisfactora de un deseo encubierto, lo cual nos pondría en deuda con quienes promovieron tal idea: Normand Holland y David Bleich. ${ }^{1}$ En todo caso, se trata de ir al libro motivo de nuestros intereses con un prurito de divertimos algunos momentos, dejando fuera todo propósito ulterior. Así leímos por vez primera "La siesta del martes", cuento que Gabriel García Márquez (Aracataca, Colombia, 1928) publicó en 1962; e incluso "La Sunamita", de Inés Arredondo (Culiacán, Sinaloa, 1928-1988), perteneciente al libro inicial de esta narradora: La señal, 1965.

Esas lecturas se cumplieron poco después de publicarse los textos y las hizo un hombre joven dispuesto a gozar la escritura de dos autores que le parecían dignos de atención. Años después, ya no tan joven, ese hombre volvió a los cuentos y entabló con ellos relaciones de otra índole, ya tocadas ( ¿será teñidas mejor palabra?) por una necesidad de esas que llamamos académicas. Porque ambos textos fueron parte de un programa sobre cuento contemporáneo, impartido en la Universidad Brigham Young, de Utah, en 1993. Uno tercero se les unió, también como parte de aquel programa: "Heat" (1992), de Joyce Carol Oates (Lockport, Buffalo, 1938). Varios más fueron examinados entonces, desde luego. Pero los tres aquí mencionados trazaron poco a poco, en nuestra memoria, puentes de unión entre sí que no parecian darse con las demás lecturas, y que no fueron, al principio, obvios a nuestra conciencia de lectores.

Sin embargo, el trabajo ocurrido en la oscuridad del cerebro de pronto nos hizo alertarnos a ciertas coincidencias, a ciertos asomos de igualdad, que por

' J. A. CudDon, Dictionary of Literary Terms and Literary Theory, p. 771. 
contraste, y en paradoja, daban un nuevo aspecto a las desigualdades. $Y$ sin nosotros saberlo, esa alerta fue el inicio del ensayo que hoy escribimos. Ensayo donde igualdades y diferencias procurarán hablar del sentido que en esos cuentos hemos encontrado. Vayamos a ellas.

Como hemos señalado, dos de los cuentos pertenecen a los sesentas y el tercero apareció en los noventas. Sin duda esto debiera establecer algún cambio en la propuesta fundamental de los textos pero, ¿no se habrá adivinado ya?, la realidad es otra: en lo más hondo de lo que se está analizando mediante la escritura hay una similitud inamovible: la naturaleza humana. $O$ precisándolo más, el hecho de que esa naturaleza humana aspire a lo luminoso pero se empantane en lo oscuro. Arredondo, García Márquez y Oates parecen preguntarse indirectamente por qué habrá de ser así. Y entonces, obediencia inevitable de los lectores al texto, terminamos preguntándonos lo mismo.

Partamos de una primera zona de coincidencia: el ámbito donde se cumplen las narraciones. Los tres autores han elegido un pueblecillo de provincia. La razón es fácil de suponer: se da en estos lugares un estrechamiento (y una cosificación) de la actitud moral. Es decir, el control sobre la conducta humana es más incisivo porque hay menos espacio qué vigilar. Por otro lado, estos pueblos sencillos y alejados de la urbe defienden con mano severa sus costumbres antiguas, pues en ellas tienen la mejor vía para perpetuarse. Así, la moral pueblerina camina la ruta de los mandamientos inamovibles. Al ser lo geográfico escaso en dimensiones, todos viven ante la mirada de todos y la intimidad es más un anhelo que una situación real. Si acaso, puertas adentro, se da un resquicio para la libertad personal. Pero no deja de ser sintomático que la imaginación popular atribuya a esas interioridades barruntos de pecado.

En tal sentido, los tres cuentos oponen a esa conducta general y dogmática una desaprobación que no surge en ningún párrafo airado, sino en el sucederse trágico de los hechos. En otras palabras, los autores entretejen su posición a la trama y dejan que ésta hable por si sola. De esa manera, las presiones sociales ( $y$ en los tres casos pueblerinas) llevan a la Sunamita a un matrimonio desaconsejable, hurgan con ojos demasiado curiosos e inmisericordes en la visita de una madre hundida en el dolor (García Márquez) y consideran que hubo un asomo de justicia en la muerte de unas gemelas y en la muerte posterior de su asesino (Oates). Y un intimo regocijo parece asentarse en el espíritu de los lugareños cuando asi de fácilmente pueden explicarse la maldad humana, sin comprender el grado de culpa que les cabe en haberla provocado mediante su inmisericorde y parcial vara de medir.

¿Recordaremos el inicio de Al filo del agua (1947)? "Pueblo de mujeres enlutadas". Bastan esas cuatro palabras para que Agustín Yáñez deje clara la intención de su novela: examinar la presencia hipócrita y beata de la Iglesia.

\section{Guan Carlos $\mathscr{H}$. Vera}


Pueblos son aquellos de los cuentos que examinamos, y en ellos la Iglesia cumple ese mismo papel de inquisidora que se ha disfrazado de madre bondadosa. Allí, en esos pueblos, ninguna dificultad le impide tirar de las riendas porque se vive una endogamia social excesiva: la mirada general penetra sin recato en las intimidades, a la busca de pecadillos y de pecados aprovechables para ejercer en los otros un acto de castigo en ocasiones muy cuestionable.

Si abordamos los tres cuentos desde tal perspectiva, es necesario comenzar por el de García Márquez. La razón es sencilla: en él, la Iglesia tiene un papel meramente burocrático y no hay presencia obsesiva del mal. Veamos por qué. Una extraña llega a un pueblo "más grande pero más triste que los anteriores". ${ }^{2}$ Un agobio de calor ausenta de las calles a los habitantes. Acompañada de su hija, la mujer busca al cura. Un asomo de curiosidad se inicia en la población, pero aún sin más intención que la curiosidad misma. El sacerdote, dedicado a una siesta reparadora, no quiere, de primera intención, recibir a la desconocida. Ésta insiste hasta vencer la resistencia del ensotanado. Cuando éste aparece, su comportamiento es lo que cabe describir como de hastío: cumple el hombre sus funciones con un desgano excesivo, proveniente de la rutina, que se romperá, desde luego, al saber quién es la mujer y el motivo de su visita.

No hay, en el cuento de García Márquez, sino la exposición de un hecho siempre verificable: ni siquiera la Iglesia escapa de los cosificadores mecanismos de la rutina. Es tal la critica hecha. La Iglesia no se interesa en comprender las razones de la conducta humana, sino en clasificarla y, de ser el caso, aplicarle un castigo mediante una cartilla moral inamovible. En cuanto al mal, presentado en el texto, radica en una curiosidad malsana ante la presencia de un ser en desgracia. Con ritmo lento pero de efecto acumulativo, la población va ejerciendo la agresividad de su presencia, y en el hecho de ese crecimiento enfermizo se da una intimación de amenaza para la mujer y su hija. Calladamente, la trama insinúa el peligro y, entonces si, el cura despierta a la obligación de su oficio y procura escudar a la visitante. Pero lo hace queriendo hurtarla a la curiosidad mediante una huida por la puerta trasera. Ese sacerdote no es capaz de salir por la frontal acompañando a la protagonista del cuento. Ésta, con dignidad que la eleva por encima del amontonado conjunto de lugareños, elige salir por el frente y con el simple hecho de avanzar por esas calles da un bofetón a los curiosos. Si la Sunamita elige conformarse con la imagen pública que de ella se tiene, esta madre elige satisfacer la curiosidad pública. Pero en ambos casos las protagonistas utilizan el mecanismo de insulto que se les dirige para mostrar su desprecio por el medio circundante.

${ }^{2}$ Gabriel García Márquez, “La siesta del martes”, en Todos los cuentos, p. 120. 
Sin duda, en el cuento comentado no hay mayores disquisiciones en torno de la Iglesia. Éstas crecen en el territorito cubierto por Inés Arredondo. Cuando a la protagonista se le aconseja matrimoniarse con un pariente anciano y en tránsito a la muerte, la impulsan a la aceptación hablándole de caridad cristiana y de conveniencia monetaria. Ella acepta, pero poco a poco sabremos que el anciano resistirá la enfermedad primero, y la vencerá después, para exigir, enseguida, sus derechos de amo y señor de la Sunamita. Ella, entrampada en una situación denigrante, acude con el sacerdote en busca de consejo. Se le da. En caso de no volver a casa, la joven provocará la muerte del esposo, pues "si no vas será un asesinato. Procura no dar ocasión, encomiéndate a la Virgen, y piensa que tus deberes..." $\mathrm{Y}$ viene el asesinato espiritual de la muchacha, al que nadie da importancia. Aquí, el sacerdote recurre a las fórmulas que su oficio le ha momificado a lo largo de los años. No hay en él la capacidad de mirar cada situación como única. Habiendo vuelto su ideología una cama de Procusto, en la cual acomoda la vida de sus feligreses, no importa que haya que desvirtuarla para que el acomodo se cumpla.

Oates enfoca el problema desde otro ángulo. Desde luego, a pueblo pequeño corresponde sacerdote pequeño. Tan pequeño que es casi invisible. Es decir, aquí lo importante y subrayado es que la religión misma provoca ciertas conductas indebidas. En el cuento se lleva a cabo un asesinato. Si en "La Sunamita" fue de orden espiritual, doble filo tiene el caso que nos ocupa: la muerte fisica de dos adolescentes y la espiritual de una familia. La segunda es causa de la primera. En tal unión se basa la lectura que podemos hacer de la trama. Por tanto, en Oates dejamos la burocracia eclesiástica fuera de los hechos y nos adentramos en las complejas ramificaciones de la religión en sí. Roger Whipple, el asesino, es un chico que asiste a la escuela dominical, colecciona estampas bíblicas y su padre lo disciplina "the way you might discipline a big dog or a horse". ${ }^{4}$ Familia metodista, la de Roger cumple celosamente todos los mandatos religiosos. Según entendemos, los cumple de manera excesiva y provoca el mal que intenta esquivar. La paradoja es clara: cuando una ideología se vuelve dogma, aniquila en el hombre su capacidad de bondad y de discernimiento.

El punto unificador de los tres cuentos es justo esa paradoja. Los une, asimismo, el que la inocencia termine siendo la víctima. En los tres casos, uno o varios personajes pagan la carga de equivocaciones surgida del entorno social que los envuelve. García Márquez, lo dijimos ya, otorga a su protagonista una

${ }^{3}$ Inés ARRedondo, "La Sunamita", en Obras completas, p. 96.

"Joyce Carol OATES, "Heat", en J. C. OATES, comp., The Oxford Book of American Short Stories, p. 610. 
dignidad que la pone por encima de la malsana curiosidad pueblerina. Esa dignidad es el comentario más acerbo a la pequeñez humana. En "La Sunamita" un ser inicialmente limpio termina preso de lo que el pueblo llama "pecado"; en otras palabras, cuando la narradora homodiegética se ve obligada a cumplir los preceptos religiosos, éstos la aniquilan por dentro, le secan el alma y la orillan a un comportamiento cuestionable, que ella asume con un cinismo atribuible a la traición sufrida por la mujer. En Oates ocurre lo mismo, las situaciones son las siguientes: se lleva a cabo el asesinato de dos adolescentes traviesas pero, finalmente, ingenuas, y existe la incomprensión del asesino (un débil mental) respecto de su acción criminal y el desquiciamiento espiritual de quien narra, una mujer testigo de los hechos cuando era adolescente, y cuya vida se desmorona a partir de allí. Tres víctimas, pues, en "Heat", el cuento de Oates. Diriamos, entonces, que la inocencia no tiene defensa cuando sufre el ataque de las supuestas buenas intenciones del dogmatismo o de la ceguera ideológica. Lo más grave de todo es que ese dogmatismo, esa ceguera, atribuye la culpa de los sucesos a la inocencia. Escudado en su propia indole, hace de la víctima excusa para quedar libre de cualquier acusación. Y, paradoja de tal paradoja surgida, termina siendo, de alguna manera, víctima de su propia condición: la ceguera que padece nos hace verlo como deficiente en su proceso moral. Pero esa comprensión se da en nosotros, los lectores. Si el dogmatismo comprendiera su naturaleza dogmática, allí mismo comenzaría una modificación en su esencia.

Pero los tres cuentos manejan con distinta profundidad la cuestión que venimos examinando. "La siesta del martes" no se asoma a ninguna consideración metafísica, y toda la base del cuento es de índole social, pues elige una anécdota directamente relacionada con la situación económica de los personajes. A nadie le preocupa el más allá, ni siquiera al sacerdote, tan simbólicamente dedicado a una siesta cuando se le necesita. En "La Sunamita", desde la entrada, el subtexto establece las condiciones del juego: "Tensa, concentrada en el desafio que precede a la combustión, la ciudad ardía en una sola llama reseca y deslumbrante". ${ }^{5}$ No hace falta mucha malicia de lector para comprender que la imaginería utilizada nos lleva a pensar en el infierno. Muchos otros datos adicionales remachan tal intuición. Así, el calor físico de un verano oprimente significa el calor espiritual de una situación exacerbada y exacerbante que la protagonista vive. Dicho con sencillez, su infierno es de este mundo: la vida de casada y la vida posterior, cuando muere el esposo y como venganza contra todo y contra todos la mujer decide entregarse a los placeres del cuerpo.

51. ARredondo, "La Sunamita", en op. cit., p. 88. 
Debemos incluir en este recuento el que se le haya quitado la posibilidad de alcazar la felicidad en la sencillez de una existencia sin complicaciones.

En "Heat", la hondura de estas consideraciones es definitivamente mayor. Partamos de una cita, si bien recordando que el discurso es homodiegético: "Because death was coming for them, it had to happen one way or another [...] If you believe in God you believe that. And if you don't believe in God it is obvious". ${ }^{6}$ Véase que la narradora abre la opción de dos explicaciones, dejando al lector la oportunidad de elegir. Pero si elige a Dios como razón de los sucesos, enseguida viene la segunda etapa: ¿por qué se da un mundo asi? En la obra de Joyce Carol Oates un algo dificil de precisar tiene una importancia definitiva: ¿por qué existe el mal y de dónde viene? Hay en esto una profunda inquietud protestante, pero tamizada ya por el descreimiento en las respuestas de orden eclesiástico o, incluso, religioso. En este sentido, el padre del asesino es la pieza central, ya que siendo metodista y creyente firme, tras el acto violento que el hijo comete sigue apoyándose en sus creencias "but none of it helped in his life".?

Sin embargo, pudiéramos decir que en ninguno de los cuentos hay culpables verdaderos. Los autores examinados no son proclives a las explicaciones en blanco y negro, que pertenecen a literaturas de naturaleza mucho más superficial y sencilla. El ser humano es complejo y compleja deberá ser la maquinaria escritural que pretenda examinarlo. Entendemos que el hombre no pueda escapar de su parte oscura y entendemos que esa parte oscura le viene de algún motor externo llamado aquí sociedad y allá Dios. Pero también entendemos que se da la posibilidad de elegir, y en tal elección se asienta la responsabilidad que nos corresponde en nuestras acciones. Por tanto, la Sunamita dice a su mundo ¿me quieres corrupta?, pues corrupta me tienes, y lo acepta con un cinismo profundamente injertado de amargura. En "La siesta del martes" la actitud de la gente proviene, en mucho, de cierta tesitura tropical, de cierta curiosidad morbosa que no pasa de hostigar a las visitantes con la insistencia de las miradas. En "Heat" la experiencia tenida de adolescente por la protagonista le causa un desgarrón en el interior que ya nunca se cura. Esa herida viene de que la narradora no alcanza a explicarse por qué habrán de suceder las cosas sin ninguna lógica visible, que fuera fácil de entender por quienes presenciaron los resultados del crimen. $Y$ si bien la ausencia de explicaciones razonables es parte de los textos, en el de Oates tal ausencia cala mucho más hondo.

En el cuento de Oates no hay señales visibles de origen intertextual. Arre-

6 J. C. OATES, "Heat", en J. C. OATES, comp., op. cit., p. 613.

${ }^{7}$ Ibid., p. 618. 
dondo hace claras las suyas al remitirnos a la historia bíblica de la Sunamita en Reyes: I, 3-4, donde se cuenta cómo Abishag (y, curiosamente, el nombre de la chica significa "padre de la levedad o del error") fue elegida por ciertos emisarios del rey David, en aquel entonces de setenta años, para que durante la noche le diera calor a ese cuerpo debilitado. El texto religioso tiene cuidado en asentar "mas el rey nunca la conocio" o, en versión inglesa, "the king himself had no intercourse with her". Esto es de subrayarse porque constituye el punto de separación entre el cuento y la historia que le da origen. Según Aid to Bible Understanding, a la muerte de David la Sunamita pasó a ser una más de las incontables mujeres de Salomón y se le perdió el rastro. ${ }^{8}$ Arredondo cambia el tono de la historia, pues introduce como elemento modificador el que el tío de la protagonista sane gracias al calor de la muchacha y, en vías de plena recuperación, exija sus derechos de cama. Ahí, en la Biblia, donde Abishag no tiene voz ni voto, en "La Sunamita" la protagonista lo es todo en el texto de Arredondo, y justo la rabia ante una injusticia patente da su amargura al discurso, aunque no podemos olvidar el pecado atribuido a la heroína: aceptar un matrimonio en artículo de muerte para quedarse con la herencia del anciano. Pero es sintomático que, como lectores, justipreciemos la situación de la narradora homodiegética. Así pues, el texto citado en el epígrafe sirve como punto de separación entre la suave atmósfera bíblica y la terrible circunstancia del cuento.

García Márquez acepta sin tapujos el origen de su cuento. En plática con Plinio Apuleyo Mendoza, cuando éste le asegura: "[h]ay un cuento tuyo, 'La siesta del martes' (el mejor que has escrito, dices tú), que le debe mucho a 'Un canario como regalo', de Hemingway", 9 el narrador contesta: "Graham Greene y Hemingway me aportaron enseñanzas de carácter puramente técnico" $0 .{ }^{10}$ Precisemos la información: el cuento de Hemingway mencionado, en su versión al español, es "A Canary for One", del libro Men Without Women (1928). Narra la conversación habida entre una anciana y un matrimonio en un vagón. Ella piensa que la pareja se lleva muy bien. La línea final la desmiente: "We were returning to Paris to set up separate residences". ${ }^{11}$

El cuento arranca diciendo "The train passed very quickly a long, red stone house with a garden and four thick palm trees with tables under them in the shade". ${ }^{12}$ He aquí a García Márquez: "El tren salió del trepidante corredor de

Aid to Bible Understanding, p. 20.

9 Plinio Apuleyo Mendoza, El olor de la guayaba. Conversaciones con Gabriel Garcia Márquez, p. 51.

${ }^{10} \mathrm{Idem}$.

"Ernest Hemngway, “A Canary of One”, en Men Without Women, p. 129.

12 Ibid., p. 124. 
rocas bermejas, penetró en las plantaciones de banano, simétricas e interminables, y el aire se hizo húmedo y no se volvió a sentir la brisa del mar". ${ }^{13}$ Desde luego, la coincidencia es circunstancial. La imagen del tren en Hemingway puso en marcha la imagen del tren en el colombiano, pero de ahí no pasa. Por tanto, la relación entre los dos cuentos es meramente de orden físico, no espiritual, si se nos permite tal descripción. La trama y las intenciones temáticas los separan definitivamente a partir de esa imagen inicial compartida.

Por tanto, la intertextualidad es de peso decisorio en "La Sunamita"; de indole superficial en García Márquez, y no parece existir en Oates. Por otro lado, los tres autores necesitaron un ámbito pequeño y muy circunscrito, donde el peso de la vigilancia mutua fuera uno de los elementos de incomodidad para los personajes y, desde luego, para el lector. A los tres pueblos se les da una atmósfera de calor agobiante, que muy claramente sirve como exacerbadora de los estados de ánimo y como símbolo del infierno que se vivirá o se está viviendo. En los tres cuentos hay una presencia femenina sobre la que se reflejan los hechos y, en dos de los casos, narradora de los mismos. Parece natural, porque en esos ámbitos la situación de la mujer está perfectamente constreñida a ciertas labores subordinadas y, en realidad, a la de ser objeto. En los tres casos el texto opta por la defensa indirecta de esos personajes femeninos y se transforma, sin olvidar sus perentorias funciones estéticas, en vía de crítica. A ello se aboca una prosa cuya eficacia radica en la capacidad de denotar, de revelar lo oculto, de trabajar con los matices y las sugerencias.

De esta manera, tres cuentos nos permiten comprobar que en la literatura las coincidencias no son sino eso, coincidencias, y que cada autor levanta su mundo literario con base en mirar esas coincidencias con perspectiva propia.

\section{Bibliografía}

Aid to Bible Understanding. Nueva York, Watch Tower Bible and Tract Society of Pennsylvania, 1971.

ARREDONDO, Inés, "La Sunamita", en Obras completas. México, Siglo XXI, 1988, pp. 88-96. (Serie Los once ríos)

CudDon, J. A., Dictionary of Literary Terms and Literary Theory. Londres, Penguin Books, 1992.

${ }^{13}$ Ibid., p. 119. 
GARCÍA MÁRQUEZ, Gabriel, "La siesta del martes", en Todos los cuentos. México, Seix-Barral, 1984, pp. 119-125. (Serie Obras maestras del siglo $\mathrm{xx})$

HEMINGWAY, Ernest, "A Canary of One", en Men Without Women. Harmondsworth, Penguin Books, 1955, pp. 124-129.

MENDOZA, Plinio Apuleyo, El olor de la guayaba. Conversaciones con Gabriel Garcia Márquez. México, La Oveja Negra/Diana, 1982.

OATES, Joyce Carol, "Heat", en J. C. Oates, comp., The Oxford Book of American Short Stories. Nueva York, Oxford University Press, 1994, pp. 607-619. 